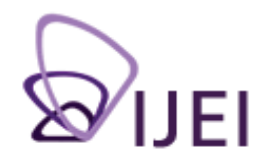

International Journal for Educational Integrity

\title{
The missing meso: Variation in staff experiences of an academic practice initiative and lessons for educational change
}

\author{
Patrick Baughan \\ City University London, United Kingdom \\ p.baughan@city.ac.uk
}

Keywords: academic practice, plagiarism prevention, phenomenography

\begin{abstract}
This paper examines variation in change agents' experiences of an intended culture change, following their implementation of an organisation-wide initiative at a single university. The purpose of the initiative was to promote better understanding of a range of academic practice and academic conduct issues amongst students and staff, and generate an institution-wide culture change. The change agents were interviewed and resulting data analysed using the phenomenographic approach, from which four qualitatively different conceptions were developed. The results suggest that a full culture change has not occurred, but that instances of localised changes have taken place. Drawing on two theoretical models, it is argued that in initiatives of this type, greater account needs to be taken of the meso level - cultures and practices in departmental and programme contexts - and that such meso level considerations should be used to complement central planning approaches adopted by academic leaders who design such initiatives.
\end{abstract}

\section{Introduction}

In recent years, many universities have organised schemes or initiatives concerned with the enhancement of study skills, plagiarism prevention, or other areas of academic practice. Morris (2010) has discussed a variety of strategies and resources that have been used to promote academic integrity and discourage plagiarism, within both departmental and institutional contexts. This paper documents a phenomenographic research project, the purpose of which was to explore variation in change agents' experiences of one such, organisation-wide scheme, entitled the Educational Development Associate Initiative. Its overall purpose was to promote better understanding of a range of academic practice and conduct issues amongst students and staff and generate a resultant culture change across the university identified as a 'culture of good academic practice'. The study examines the experiences of the change agents who implemented the initiative, focusing on their conceptions of the intended change, addressing the following question: What variation occurred amongst a group of change agents in their experiences of undertaking an academic practice initiative, in particular, the extent to which they feel it achieved a culture change?

The report discusses the study and then draws out broader lessons for achieving culture change in organisation-wide, academic practice initiatives of this type. It will be argued that when designing such initiatives, in order for culture change to have a better chance of occurring, academic leaders and policy-makers need to take greater account of the meso level - that of the department or small-scale workgroup. The

The International Journal for Educational Integrity is available online at:

http://www.ojs.unisa.edu.au/journals/index.php//JEI/

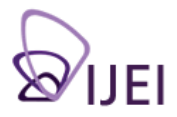


analysis is informed through a theory of educational change proposed by Trowler $(2005,2008)$ and Alvesson's $(1993,2002)$ notion of multiple cultural configurations. The key tenets of these works are blended together to support the case made here that such a hybrid approach provides a more useful and intricate tool for informing change than 'top-down' and technical rationalist approaches.

There are plenty of case studies documenting how institutions have set up school or faculty based initiatives, in which Academic Conduct Officers (or equivalent) have been appointed, but these have normally been for the purpose of intervening in suspected academic misconduct cases after they have occurred, whether that be with respect to chairing panels or counselling students found 'guilty' of misconduct in the first place. A distinctive characteristic of the innovation discussed here was that change agents undertook projects within their schools to promote good academic writing and reduce the opportunities for, and likelihood of academic misconduct cases occurring in the first place through a more learning-based approach.

Following this section, backgrounds about the organisational context and setting up of the initiative are provided. The theoretical framework is then elucidated on. This is followed with an explanation for the decision to adopt the phenomenographic approach and details of the implementation of the research. The results are presented and subsequently discussed. Finally, the conclusion reconsiders the results in light of the research question and offers some broader comments. The term 'initiative' is used to refer to the scheme as a whole, which was structured into three projects.

Educational Development Associates (EDAs) were required to implement each of the three projects within their respective schools. In the context of this study, a 'school' refers to a collection of academic departments under the leadership of a Dean.

\section{The organisation}

The initiative was undertaken at a UK University, with a student population of approximately 17,000 . It has well-established policies about, and support systems for, academic practice and academic conduct issues. However, over a period of years, the broader context has changed, and it has been variously suggested that there are now more opportunities for students to become involved in academic misconduct, either accidentally or intentionally (Blum, 2009; Carroll, 2007; Sutherland-Smith, 2008). Whilst data suggested no upsurge in cases at the institution being studied, it was felt that there was a need for a more proactive approach to be taken, to ensure that students and staff were furnished with a fuller understanding of what plagiarism is and how to avoid it, as well as gain an understanding of academic practice skills relevant to their programme. It is these factors that led to the development of the initiative.

\section{Setting up the initiative}

The starting point was the establishment of a new steering group, which included membership from academic departments and central service sections across the university. The group confirmed the need for a longer term approach, the aims of which were set out as follows: to promote good study skills by way of positive, student -learning methods; to work across the whole university; and to achieve the above by way of a series of schools-based projects. In doing so, a central aim was to create a 'culture of good academic practice'. The initiative was organised into three projects, to be implemented by the aforementioned change agents (also referred to as EDAs), each of whom was an existing member of academic staff, taking on an extended professional role. One EDA was recruited for each school, except for the largest school, for which two were recruited. The appointment process of EDAs was carried out within individual schools. Some schools invited any interested staff (within the respective school) to apply, but in other cases a particular person was approached by 
the Dean of the relevant school. EDAs were each paid a monthly 'responsibility allowance' for the additional work which their new roles entailed. The initiative (in the form of its three constituent projects) was implemented over a two and a half year period, with funding from both internal and external sources secured for this time period.

Planning was also guided by research on academic conduct and assessment. This included literature on student writing and plagiarism prevention (Stefani \& Carroll, 2001), guidance about student centred assessment approaches (Falchikov, 2004; Pickford \& Brown, 2006; Norton, 2007), and Carroll's holistic approach to plagiarism prevention (Carroll, 2007). The holistic approach is intended to provide a complete strategy that institutions can follow, seeking the development of a common understanding of plagiarism, 'designing out' opportunities for plagiarism, 'designing in' guidance for learners, and the creation of a culture where plagiarism is not accepted. Development of the initiative was informed by the view that plagiarism prevention represents a shared responsibility, in which students, staff and institution should all bear some responsibility for its avoidance, a position supported in the work of, for example, Sutherland-Smith (2008) and Hrasky and Kronenberg (2011).

It was recognised that whilst there was a single set of objectives, change agents would need some 'manoeuvring space' to implement the projects in a way which accounted for their own working contexts. However, other staff - lecturers, programme designers and others affected by the changes - were provided with rather fewer opportunities to inform design of projects. The initiative incorporated a range of central plans and processes, such as high-level objectives, inventories of actions, and progress reports mapped against actions, all of which were updated at regular meetings. Significant aspects of the initiative were characterised by a top-down, technical rationalist approach, the key tenets of which are discussed below.

\section{Approaches to culture change: A theoretical framework for the study}

There exists a rich literature on culture change and organisational change: these terms are often used interchangeably, but culture change might be considered to represent one form of organisational change (Smith, 2003) or a factor that could trigger its occurrence (Dawson, 1994). In particular, much has been written about approaches for achieving culture change. Many such approaches involve the drawing up of prescribed courses of action by policy-makers, with the expectation that change will occur once actions are undertaken. Such approaches often involve application of the technical rationalist approach or one of its variants. Technical rationalism is a centralised, top-down approach, characteristic of what Sadler-Smith and Smith (2006, p. 271) refer to as "...the plan-do-check cycle of the systematic approach" which works "...under tightly structured conditions of predictability, control and stability". The approach is detailed and its virtues elaborated in sources including Buckley and Caple (1992) and Patrick (1992), but whilst representing a popular model in higher education, it has been subject to considerable criticism. Ogbonna and Harris (2002) refer to the existence of a gap between academic theories which are critical of the idea of such approaches and the actions of practitioners in the sector who engage in interventions of this type. Sadler-Smith and Smith (2006) add that technical rationalism is behaviourist and reductionist, overlooking incidental learning and the 'messiness' of everyday practice.

There are, of course, alternative models. For example, Fullan writes of change as a journey in which organisations need to be understood as living systems (1999); he emphasises the importance of complexity and diversity when developing change processes for educational environments $(1999,2003)$, and he considers the relationship between organisational change and leadership principles (2007). However, these approaches are often practice-based (Trowler, 2005) and do not pay sufficient account of the needs of specific work groups. In larger scale educational 
initiatives, it seems reasonable to suggest that different issues and concerns may arise for particular communities within the organisation, and that it might be beneficial for some attention to be paid to these.

Trowler $(2005,2008)$ argues that there is a need to focus more at the meso level, foregrounding local contexts, such as the programme, department, or work group. He uses the conceptual device of Teaching and Learning Regimes (TLRs) to provide insights into meso level dimensions in universities which relate to change processes. TLRs involve a "constellation of moments", defined as "dimensions of culture" (Trowler, 2008, p. 23), which are interlaced in social practices. He identifies and explains eight such moments, examples of which include attribution of meanings, discursive repertoires, recurrent practices and the presence of power relations. In reality, such moments operate as a collective, interweaving with one another within the specific context. In this way, they provide an access point to the meso level approach for understanding educational change; some recent examples are provided in Bamber, Trowler, Saunders and Knight (2009). Meso theory was applied to this project as a means of considering and illuminating the findings gained in response to the original research question. Specifically, the theory was used to inform the project and cast light on what the findings reveal about culture change from the perspectives of the change agents, but it was not intended to provide a tool to measure the extent to which culture change had taken place as a result of the initiative. The project was also informed by Alvesson's $(1993,2002)$ work on culture change, which advocates that we should interpret organisations as comprising multiple cultural configurations characterised by flows of 'cultural traffic'. Alvesson's view steers us away from interpreting universities as 'total institutions' (Silver, 2003), drawing attention to a multiplicity of cross-cutting cultures across the organisation.

To sum up, the initiative was designed by a steering group and its three constituent projects were implemented by a set of change agents (EDAs). Whilst change agents were able to take some account of school needs, the initiative was also characterised largely by top-down, technical rationalist practices. However, by way of a phenomenographic study, this research argues that change initiatives may benefit from greater consideration of a meso-based perspective.

\section{The phenomenographic study}

Phenomenography is a research approach that seeks to identify variation in experiences of a particular phenomenon amongst a sample of a given population. It does not seek to identify common themes, but is concerned with differences in the way a phenomenon is experienced - in this case, the EDA initiative. It assumes that such experiences may be depicted by a limited number of qualitatively distinct categories of description (Marton, 1981). As well as identifying different categories or conceptions of a phenomenon, the researcher also seeks to develop an understanding of the meanings of those conceptions and the relationships between them (Entwistle, 1997). It is assumed that different experiences may be logically related to one another with some ways being more complex than others, such that more complex ways of experiencing include those which are less complex (Åkerlind, Bowden, \& Green, 2005). A further important attribute is its concern with the collective experience:

The essence of the approach is that it takes a relational qualitative perspective that aims to describe key aspects of variation in the collective experience of phenomena, rather than focusing on individual experience. (Trigwell, 2006, p. 367)

Phenomenography is underpinned by the constructivist principle that people create meanings of phenomena. It takes a non-dualistic ontology (Âkerlind, 2005a) and so 
does not seek to compare a 'real world' to a 'subjective world': the world and the person are understood in terms of "....an internal relation between them" (Marton \& Booth, 1997, p. 13). What matters are peoples' perceptions of the truth for them as this guides their practice (Cousin, 2009). This study sought to explore variation in experiences of culture change amongst a group of change agents. To understand this, there was a need to probe into their unique, contextualised experiences: what was it like to be a change agent in a particular school; how did each change agent perceive their role; what changes did each manage to facilitate? In circumstances in which the researcher is seeking to elicit detailed information about experiences, as well as examples and explanations of them, phenomenography can be valuable, as it seeks to explore meanings of a phenomena amongst respondents. In addition, with the change agents working in diverse school settings, it provided an appropriate approach because of its focus on variation in experience, allowing us to consider the effect of those variations on practice (Cousin, 2009).

However, as with any research approach, phenomenography has its limitations, a number of which are discussed by Cousin (2009). For example, it has a tendency to ignore the emotional dimension in learning because much of it is concerned with conceptual understandings. Nevertheless, the need for detailed accounts from change agents combined with the expectation that their experiences would be varied due to their work across a disparate school structure provided a convincing case for its use here.

\section{Research design and implementation}

When using phenomenography, researchers normally select the broadest possible sample, to maximise opportunities for variation (Ashwin, 2005; Cousin, 2009). For the present study, the population comprised ten change agents, of which eight were interviewed. Of the other two, the first left within three months of the start of the initiative, and so was not approached; the other is the author of this paper.

Nevertheless, the sample provides for considerable variation, the change agents "... being from varied disciplines, cultural backgrounds and gender, with varying experience as an academic" (Âkerlind, 2005c, p. 103). Phenomenography may be applied through a number of methods, but the semi-structured interview is the most common (Orgill, 2008) and was used here. An interview schedule was devised, comprising a list of key questions. To ensure a consistency of approach, these key questions were raised with each of the change agents. In addition, a number of optional, subsidiary questions were written, and used where necessary to probe further into the experiences of the change agents (Åkerlind, 2005c). During the interviews, each participant was invited to comment on their experiences of the initiative, especially the extent to which their experiences provided evidence, or otherwise, that culture change had occurred. They were encouraged to provide examples to illustrate experiences they described. Interviews took between 45 and 60 minutes to undertake and were recorded and transcribed verbatim, except for one, for which notes were taken. Some researchers have reported finding it helpful to start the analysis during the implementation stage, make any necessary amendments, and then complete the research (Åkerlind, 2005c; Prosser, 1994; Trigwell, 2000). For this project, an initial analysis was undertaken following completion of the fourth interview. As variation was immediately apparent, remaining interviews were undertaken without further amendments.

\section{Analysis of the data}

Analysis of results was guided by the phenomenographic approach (Marton \& Booth, 1997 ) and advice for the new phenomenographic researcher (Åkerlind, 2005a, 2005c; Åkerlind et al., 2005; Cousin, 2009). It involved the development of a set of related categories from the data obtained through the collective response of the participants, or the "...pool of meaning" (Marton \& Booth, 1997, p. 133). This necessitated selecting components of the transcripts relevant to the phenomenon, identifying qualitative aspects of variation, locating logical and hierarchical relations between the 
categories, drawing on empirical evidence to support this, and formulating an outcome space. An attempt was made to be parsimonious, yielding as limited number of categories of description as was feasible, whilst capturing the important conceptions that were expressed. To achieve this, a combined iterative and spatial approach was used. Following an initial reading of transcripts, the iterative technique necessitated re-reads, scrutinising and categorising of the data. After annotating the transcripts, cuttings were organised to enable the development of a number of data categories, each of these appearing to show qualitatively different experiences. As data analysis reached a more advanced level, it transpired that not all of these sections actually were qualitatively different, so sections were combined and some data disposed of, until a set of qualitatively distinct categories remained, and a state of 'analytic closure' (Åkerlind, 2005b) was reached. These conceptions will now be presented and explored.

\section{Conceptions of the phenomenon}

The analysis yielded four qualitatively different conceptions of the initiative. The conceptions are organised in the form of a nested hierarchy, so later ones imply an understanding of earlier ones, but earlier conceptions do not take in later ones. As explained by Ashwin (2005), since each conception is derived from an analysis of all the transcripts, it cannot be claimed that individual quotations perfectly align to particular conceptions, but instead provide a sense of that conception.

\section{Conception 1: Initiative experienced through barriers to change}

Change agents whose experiences aligned with this conception viewed the initiative by way of a number of barriers, which served to limit its impact. Barriers were of two types: those that were perceived to exist within the school in which the change agent was working and those perceived to be organisation-wide. As a result, those taking this conception spoke primarily of barriers to change as opposed to change itself. The following quotation provides an example of this in a school context:

That's by far the biggest problem here, and that's illustrated by the fact that if you go and talk to a member of staff about plagiarism issues, you know, you knock on the door and you sit down and talk up these issues, they will be nodding in agreement. You walk out of the door and you never hear of them again... People don't think there is a problem to be addressed. (EDA1)

...there is one part of the school where nothing has happened. That's an ongoing problem and it's very, extremely difficult to break that barrier in these departments. It's like a block and they just run away. (EDA5)

As mentioned, barriers to change were also reported as taking place at institutional level, with suggestions that other, concurrent initiatives made it more difficult to generate change in the context of this one:

There is a lot of change going on, and disentangling the impact of this from many other changes... it is getting drowned out with all the noise of the other things going on. (EDA4)

It appears that the aims of this initiative were becoming 'tangled up' with others. The results suggest such 'over-policy' can lead to deleterious consequences, with different policy aims conflicting with one another and leading to recipient confusion. This impacted upon receptions to aspects of this initiative, with some TLRs characterised by resistance and fatigue. 
Conception 2 : Initiative experienced as achieving change through awareness raising and dissemination of good academic practice

In this category, change agents experienced the initiative as generating change in the form of awareness raising and dissemination of more general issues that it encompassed, such as the relationship between assessment design and plagiarism prevention. Projects were interpreted as vehicles by which awareness of more general but relevant aims could be achieved:

The change primarily for me means raising awareness about something when there isn't any in some departments. For example, I can think of some departments... where there is no awareness at all of what plagiarism is, and that is a problem.... (EDA2)

...I produced some information, disseminated information for the staff, did a couple of seminars about the use of anti-plagiarism detection software, and that information was quite useful, and I also produced some exercises and I started looking at one of the areas which was the guidance given to the learners about referencing.... (EDA6)

Thus, the initiative was experienced as one primarily about dissemination and awareness raising, as opposed to one which was seeking to instigate a set of specific projects towards the achievement of a culture change. This was often because of particular expectations of change agents within their respective school contexts:

I've come to see that the best way of doing things here is to try and develop in my own work examples of good practice, and try and disseminate those... (EDA3)

...I think obviously I was expected to have a dissemination role, and it certainly linked very much with my role in the school... (EDA6)

In sum, then, this conception points to some positive effects, but not one that could be understood as a culture change.

\section{Conception 3: Initiative experienced as achieving instances of change}

The third conception was reported by change agents who experienced the initiative in terms of specific instances of change. In this category, as with the last, it was experienced as serving a dissemination role, but also as a structured entity through which attempts were made to implement a number of projects, with reported instances of actual change to practice occurring as a result. Such changes were perceived as representing specific, positive examples, as opposed to constituting a broader cultural change, and a substantial number were discussed, varying from one school to another.

We arranged a couple of hour long meetings. [For] the first meeting, we looked at what the problem was and we looked at the assessment. We - it was really me - asking this member of staff what they wanted to get out of the assessment. In other words, going through the sort of constructive alignment process. As a result of that process, we identified some mismatches between what he wanted to do and what was actually happening in the assessment. I then went away and considered, came up with some possible answers, ideas that would align these more strongly while reducing the likelihood of plagiarism, and we had a second meeting... We thought about how practical they were. The member of staff then described how they might adapt them and how he preferred to do them, and he came up with a new design which he then implemented and has been successful. (EDA1) 
I remember very clearly a girl who said, you know - I had no clue about these issues whatsoever. So I had said to her - where had you originally been a graduate from? She said - I graduated in Russia and none of this was ever told to us, we never even thought about this.... Listen to this girl, you know... so thankful, so grateful that we bothered to start there and tell them these things. (EDA5)

The second quotation demonstrates a specific instance of change achieved through the change agent working in their school context, in this case positively impacting upon a student learning experience. Whilst respondents adopting this conception provided examples of change within specific contexts, they stopped short of suggesting that broader cultural change had occurred, as this final quotation indicates:

If there was a culture change then people would be doing that without my presence by now. It would be happening by itself. As a result... I don't think we have a culture change. (EDA1)

\section{Conception 4: Initiative experienced as starting to generate cultural change}

This represents the most inclusive conception. Change agents who adopted it experienced the initiative as one that was beginning to lead to fuller culture change across the organisation. However, in each case it was indicated that culture change was in its early stages; that a full culture change had not yet been achieved.

Nevertheless, change agents identified examples of change in their experience of the initiative that they construed to be evidence of the beginnings of broader cultural change.

The initiative has been effective in achieving a culture change in a beginnings way - beginnings work to form a firm foundation. It takes time for people to learn what you can do for them. Also, it takes time for the value of what you do to be shown - so we are in the process of that being realised now. (EDA8)

...some level of culture change has started, for instance, I think it would be fair to say that for new staff that now join.... they know what the expectations are, they know how seriously we treat cases, so they join this culture... that we hope to have influenced or created. (EDA5)

\section{Discussion and broader implications}

The four conceptions illustrate varied experiences of the initiative, ranging from it being characterised by barriers to change to being interpreted as providing the beginnings of a broader culture change. They demonstrate clear variation in experiences of the phenomenon amongst the change agents. This scheme, like many others, was designed largely through application of a technical rationalist approach, yet whilst it has clearly yielded some positive outcomes, no conception reports that a full culture change has taken place. The results raise questions about the suitability of 'top-down' approaches as the dominant informant for academic practice initiatives.

Findings under Conception 1 suggest the existence of differences in experiences at departmental and school levels: some departments and schools were more receptive to the projects than others, often because staff faced particular challenges within their school contexts. Indeed, quotations under Conception 1 provide some noticeable examples of the occurrence of local level barriers. Conception 2 findings also demonstrate a particular approach to the initiative, because change agents adopting this conception appeared to feel that a dissemination role was the best method for them to work within the circumstances of their schools. However, all the conceptions point to localised instances of change taking place, as opposed to a consistent or 
cross-institutional set of results that a technical rationalist approach would presumably espouse. Similarly, change agents encountered a range of local issues and experiences in undertaking their work and implementing the projects. There were different cultures and practices within schools and departments which influenced reception, lending support to the meso level theory of change advocated by Trowler $(2005,2008)$. We can detect examples of interweaving TLR 'moments' throughout the findings: positive discursive repertoires, depicted through engagement by academics working in contexts which feature an emphasis on good teaching and learning practice; the apparent rejection of an issue to be addressed in other contexts; evidence of meso-politics within departments and schools; and the attribution of different meanings by recipients and amongst change agents themselves. In addition, the conceptions provide examples of the presence of different cultural configurations within and amongst schools and departments, similar to the model introduced by Alvesson (1993). In light of this study, culture is presented as a plural concept, as opposed to 'some thing' which can be singularly created or changed. Trowler's theory of educational change may be a more suitable informant for innovations involving attempted enhancements to academic practice, as it invites those who lead these initiatives to account for diversity in local practices and needs.

The study does have its limitations. It may have been compromised by the fact that this author was one of the change agents, though such an arrangement at least ensured a detailed understanding of the initiative. It was also small-scale, being based purely on the experiences of the change agents. Further, the use of phenomenography inevitably results in a particular type of interpretation and presentation of the data. Nevertheless, it is distinctive in offering a close-up insight into implementer experiences of a particular academic practice scheme.

The study was undertaken within a single institution, so its findings cannot be claimed to be generalisable across the sector. Nevertheless, it is suggested that these findings bear some broader implications and lessons about culture change and schemes set up to promote culture change that should be relevant to colleagues in other institutions. First, where a 'culture change' represents an aim of a scheme, it may be useful to provide a more detailed explanation of what that means and where it is intended to head towards. This study suggested the existence of different cultures within and amongst the schools, raising the question as to whether such an initiative can achieve a 'singular' culture change. Second, if it is accepted that there are cultural and practical differences amongst work groups within institutions, it would be worthwhile considering meso level needs and differences at the planning stages. Academic leaders might wish to make initial enquiries with schools and departments to establish local aims to complement and inform the institutional ones. A clearer idea of the achievements of this initiative is provided by examining instances of academic practice and plagiarism prevention enhancements within schools and departments.

Correspondingly, the results raise questions about the suitability of technical rationalist approaches as the dominant informant for educational change schemes. As indicated by Sadler-Smith and Smith (2006), whilst these approaches may provide a starting point for the new change agent, they obscure local issues and practices. Instead, the findings provide support for Trowler's $(2005,2008)$ theory of educational change, because it invites those who lead these initiatives to account for diversity in practices and cultures within the organisation. If these issues are considered in the planning stages, policy-makers will gain a better understanding of the environments that they are seeking to effect change upon. The results of this study provide evidence that theories by Trowler and Alvesson are useful for informing contemporary educational change, because each offers a theory for educational institutions as they are now: large, diverse, plural, complex.

Further, this initiative occurred at a time of other educational change. The results suggest that such conditions of 'over-policy' can lead to negative consequences, with 
different policy aims becoming muddled up with each other, leading to confusion. Academic leaders need to manage the timing of policy schemes to negate or reduce such effects.

However, there is an additional point to be made, drawing us away from a purist application of the meso approach. Clearly, universities must take seriously the important work of policy-making units and committees. Universities have significant, influential policy-making units, such that adoption of a meso approach requires that their roles, expertise areas and practices are accounted for too. But this central component needs to be undertaken in combination with meso level considerations at all stages: creation, design, implementation, evaluation, follow up, such that our dominant precursor or guide to change is at the meso level itself.

Finally, the results provide the opportunity for some comment to be made about plagiarism prevention frameworks, such as those of Carroll (2007) and Blum (2009), the former of which shaped the design of the initiative. Both frameworks provide discussions of culture in relation to plagiarism prevention: the former makes reference to the need to develop a culture in which the profile of academic misconduct is raised and not accepted through its adoption of a holistic approach; the latter discusses the need to account for the existence of different student and staff cultures. Carroll's work was found to be very valuable, and her approach has been influential in numerous countries. Nevertheless, a further degree of sophistication might be added to such frameworks if they too considered the cultural concept at more localised levels.

Overall, whilst it is not claimed that the findings of the study are directly generalisable or transferable, they do bear lessons that should be of value to others involved in change initiatives, particularly of the pedagogical orientation which has formed the focus of this article.

\section{Closing comments}

This paper documents a phenomenographic research project which explored variation in experiences of culture change amongst a group of change agents, for a single organisational innovation. The analysis of data led to the development of four qualitatively different conceptions. The findings suggest that whilst various instances of change took place, a full culture change has not yet occurred. Accounting for these findings, it is argued that when designing and undertaking academic practice and plagiarism prevention initiatives of this type, there is a need to shift away from a reliance on technical rationalist approaches. Instead, more modern approaches such as that set out by Trowler $(2005,2008)$ and Alvesson $(1993,2002)$ can provide valuable tools and frameworks to be guided by, as they offer a more intricate view of the patchwork of interests involved in and affected by educational change.

\section{References}

Åkerlind, G. (2005a). Variation and commonality in phenomenographic research methods. Higher Education Research \& Development, 24, 321-334.

Åkerlind, G. (2005b). Phenomenographic methods: A case illustration. In J. Bowden \& P. Green (Eds.), Doing developmental phenomenography. Melbourne: RMIT University Press, 103-127.

Åkerlind, G. (2005c). Learning about phenomenography: Interviewing, data analysis and the qualitative research paradigm. In J. Bowden \& P. Green (Eds.), Doing developmental phenomenography. Melbourne: RMIT University Press, 63-73.

Åkerlind, G., Bowden, J., \& Green, P. (2005). Learning to do phenomenography: A reflective discussion. In J. Bowden \& P. Green (Eds.), Doing developmental phenomenography. Melbourne: RMIT University Press, 74-100. 
Alvesson, M. (1993). Cultural perspectives on organisations. Cambridge: Cambridge University Press.

Alvesson, M. (2002). Understanding organisational culture. London: Sage.

Ashwin, P. (2005). Variation in students' experiences of the 'Oxford Tutorial'. Higher Education, 50, 631-644.

Bamber, V., Trowler, P., Saunders, M., \& Knight, P. (Eds.). (2009). Enhancing learning and teaching in higher education: Theory, cases, practices. Maidenhead: Open University Press/SRHE.

Blum, S. (2009). My Word! Plagiarism and college culture. Ithaca/London: Cornell University Press.

Buckley, R., \& Caple, J. (1992). The theory and practice of training. London: Kogan Page.

Carroll, J. (2007). A handbook for deterring plagiarism in higher education (2nd ed.). Oxford: The Oxford Centre for Staff and Learning Development, Oxford Brookes University.

Cousin, G. (2009). Researching learning in higher education: An introduction to contemporary methods and approaches. London: SEDA \& Routledge.

Dawson, P. (1994). Beyond conventional change models: A processual perspective. Asia Pacific Journal of Human Resources, 34(2), 57-70.

Entwistle, N. (1997). Introduction: Phenomenography in higher education. Higher Education Research \& Development, 16, 127-134.

Falchikov, N. (2004). Improving assessment through student involvement. London: Routledge Falmer.

Fullan, M. (1999). Complexity and the change process. London: Falmer Press.

Fullan, M. (2003). Change forces with a vengeance. London: Routledge Falmer.

Fullan, M. (2007). Leading in a culture of change. San Francisco, Jossey-Bass.

Hrasky, S., \& Kronenberg, D. (2011). Curriculum redesign as a faculty-centred approach to plagiarism reduction. International Journal for Educational Integrity, $7(2), 23-36$.

Marton, F. (1981). Phenomenography - describing conceptions of the world around us. Instructional Science, 10, 177-200.

Marton, F., \& Booth, S. (1997). Learning and awareness. New Jersey: Lawrence Erlbaum Associates.

Morris, E. (2010). Supporting academic integrity: Approaches and resources for higher education. York: Higher Education Academy/JISC Academic Integrity Service. Retrieved September 1, 2012, from http://www.heacademy.ac.uk/ assets/documents/academicintegrity/SupportingAcademiclntegrity.pdf.

Norton, L. (2007). Using assessment to promote quality learning in higher education. In A. Campbell \& L. Norton (Eds.), Learning, teaching \& assessing in higher education: Developing reflective practice. Exeter: Learning Matters, 92-101.

Ogbonna, E., \& Harris, L. C. (2002). Managing organisational culture: Insights from the hospitality industry. Human Resource Management Journal, 12(1), 33-53.

Orgill, M. (2008). Phenomenography. Retrieved September 1, 2012, from www. minds. may.ie/ dez/phenom.html.

Patrick, J. (1992). Training research and practice. London: Academic Press.

Pickford, R., \& Brown, S. (2006). Assessing skills and practice. London: Routledge.

Prosser, M. (1994). Some experiences of using phenomenographic research methodology in the context of research in teaching and learning. In J. Bowden \& E. Walsh (Eds.), Phenomenographic research: Variations in method. Melbourne: Royal Melbourne Institute of Technology, 31-43.

Sadler-Smith, E., \& Smith, P. (2006). Technical rationality and professional artistry in HRD practice. Human Resource Development International, 9(2), 271-281.

Silver, H. (2003). Does a university have a culture? Studies in Higher Education, 28 (2), 157-169. 
Smith, M. (2003). Changing an organization's culture: Correlates of success and failure. Leadership \& Organization Development Journal, 24(5), 249-261.

Stefani, L., \& Carroll, J. (2001). A briefing on plagiarism (Assessment Series No. 10). Learning and Teaching Support Network Generic Guidance.

Sutherland-Smith, W. (2008). Plagiarism, the internet and student learning: Improving academic integrity. London: Routledge.

Trigwell, K. (2000). Phenomenography: Discernment and variation. In P. Trowler (Ed.) (2005). A sociology of teaching, learning and enhancement: Improving practices in higher education. Revista de Sociologia, 76, 13-32.

Trigwell, K. (2006). Phenomenography: An approach to research into geography education. Journal of Geography in Higher Education, 30(2), 367-372.

Trowler, P. (2005). A sociology of teaching, learning and enhancement: Improving practices in higher education. Revista de Sociologia, 76, 13-32.

Trowler, P. (2008). Cultures and change in higher education: Theories and practices (Universities into the $21^{\text {st }}$ Century). USA: Palgrave Macmillan.

\section{About the author}

Patrick Baughan is a Senior Lecturer in Educational Development at City University London. His academic background lies in the disciplines of psychology and sociology, but since joining City, he has worked in the field of educational development and higher education studies. Patrick's research areas include educational integrity and plagiarism prevention, assessment and feedback and, more recently, sustainability issues and policies in higher education. Patrick undertakes a number of roles for the (UK-based) Society for Research in Higher Education (SRHE) and is both a Fellow and Academic Associate of the Higher Education Academy (HEA). 